\title{
Cyanogen Bromide Formation from the Reactions of Monobromamine and Dibromamine with Cyanide Ion
}

Hongxia Lei, Roger A. Minear and Benito J. Mariñas*

Department of Civil and Environmental Engineering, University of Illinois at UrbanaChampaign, Urbana, Illinois 61801

\section{SUPPORTING INFORMATION}

This section presents additional information concerning results and modeling for experimental sets MB-

4-7 (Figure S-1) and DB-2,4 (Figure S-2) discussed in the main manuscript.

\footnotetext{
* Corresponding author email: marinas@ uiuc.edu; Phone: (217)333-6961; Fax: (217)333-6968
} 


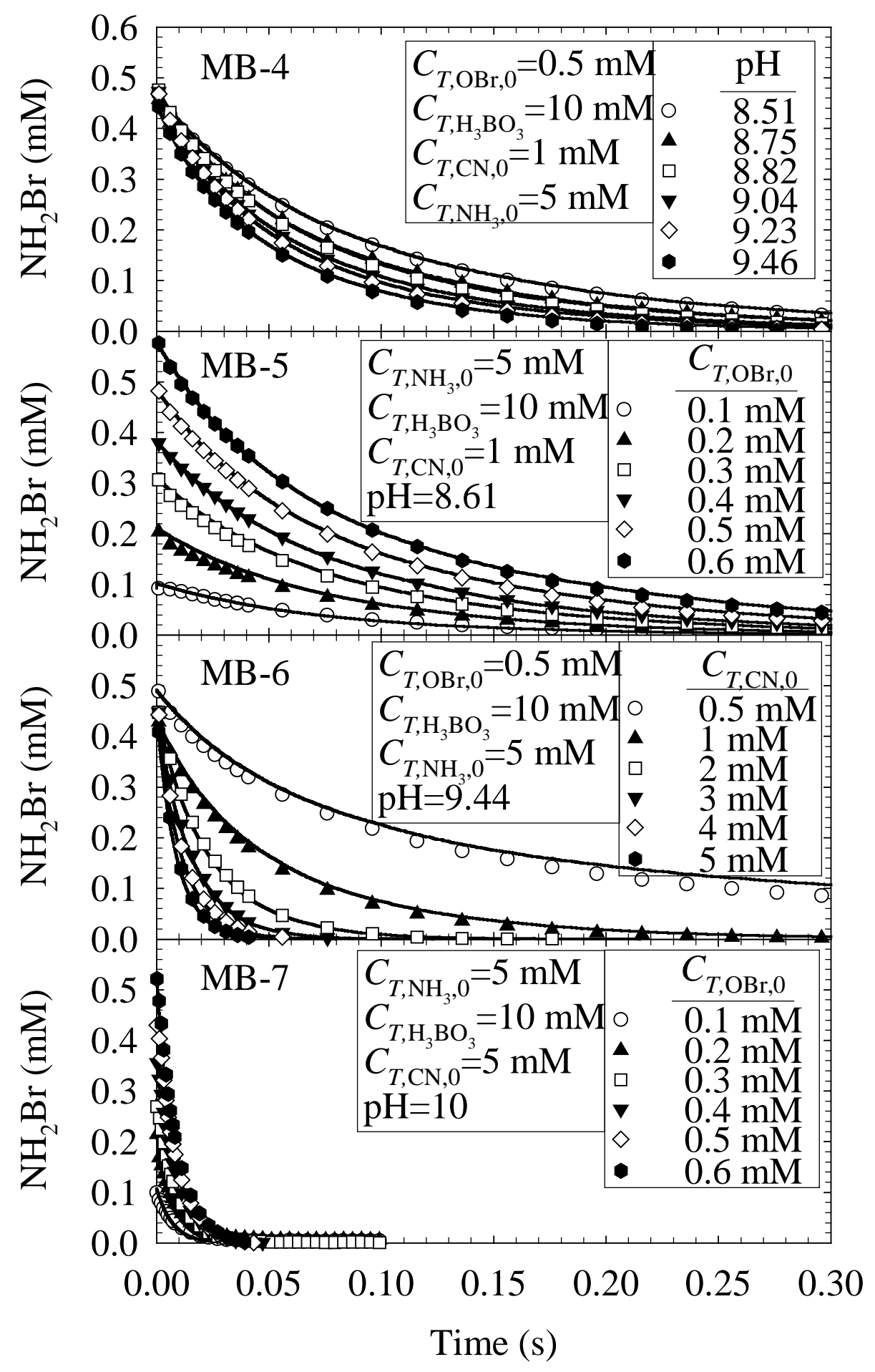

Figure S-1. Effect of initial total cyanide concentration (experimental sets DB-2,4) on experimental (symbols) and predicted (lines) bromamines concentration traces resulting from reacting $\mathrm{NH}_{2} \mathrm{Br} / \mathrm{NHBr}_{2}$ mixtures with $\mathrm{CN}^{-}$at $\mu=0.1 \mathrm{M}\left(\mathrm{NaClO}_{4}\right), 25.0 \pm 0.1{ }^{\circ} \mathrm{C}$, and the additional specific conditions indicated in Table 2 of the main manuscript. 


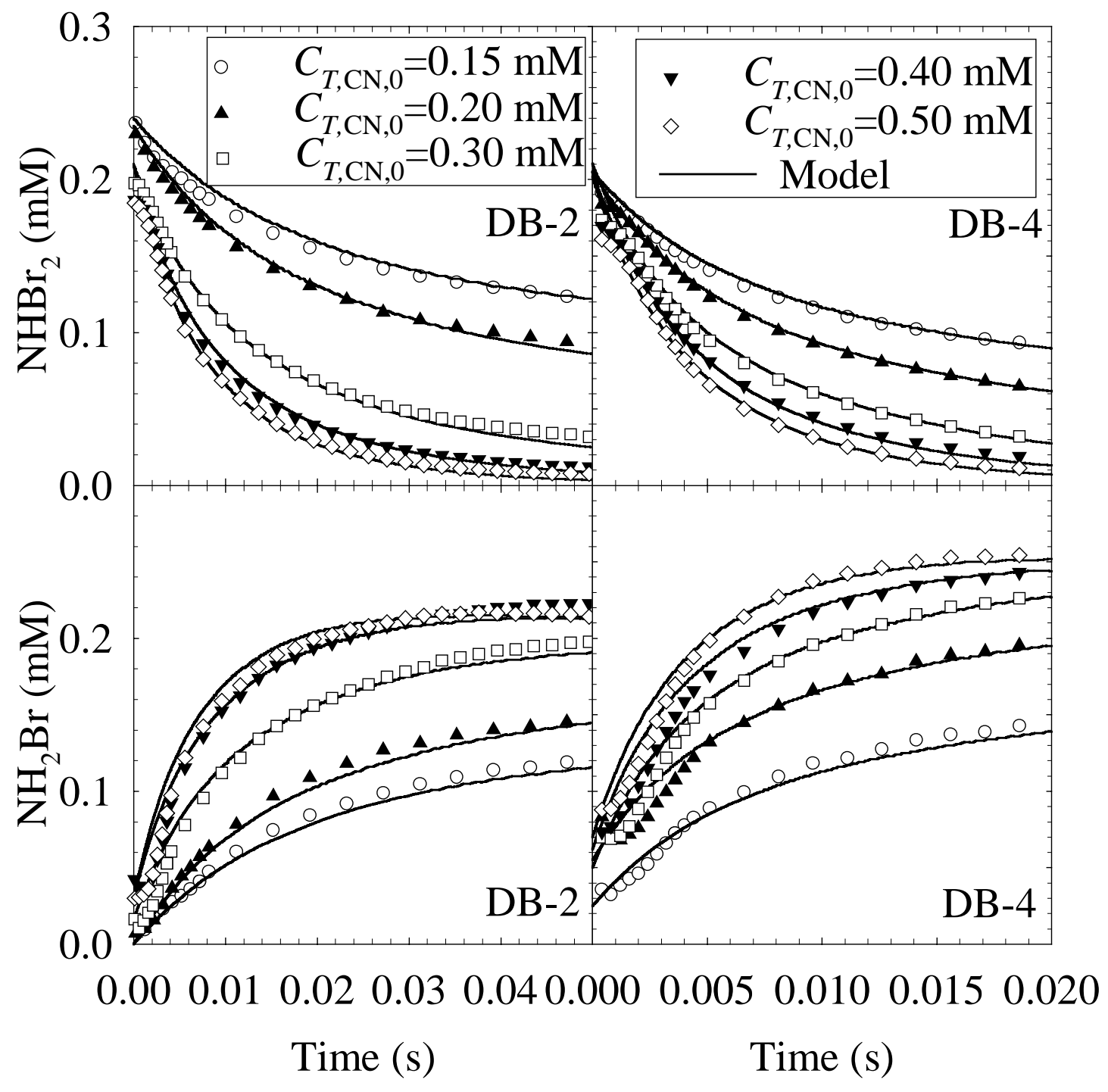

Figure S-2. Effect of $\mathrm{pH}(\mathrm{MB}-4)$, initial total bromine concentration (MB-5,7), and initial total cyanide concentration (MB-6) on experimental (symbols) and predicted (lines) monobromamine concentration traces resulting from reacting $\mathrm{NH}_{2} \mathrm{Br}$ with $\mathrm{CN}^{-}$at $\mu=0.1 \mathrm{M}\left(\mathrm{NaClO}_{4}\right)$ and $25.0 \pm 0.1{ }^{\circ} \mathrm{C}$, and the additional specific conditions indicated in each plot 